\title{
Trained and Amphetamine-Induced Circling Behavior in Lesioned, Transplanted Rats
}

\author{
Jerry B. Richards, Karen E. Sabol ${ }^{1}$, Evelyn H. Kriek and Curt R. Freed ${ }^{2}$ \\ Division of Clinical Pharmacology and Toxicology, University of Colorado Health Sciences Center \\ 4200 East Ninth Avenue, C-237, Denver, Colorado 80262, USA \\ 1Present address: Department of Pharmacological and Physiological Sciences, University of Chicago \\ 947 E. 58th street, Chicago, IL 60637, USA
}

\section{SUMMARY}

Rats were trained to turn for water reinforcement and then were given unilateral 6hydroxydopamine lesions. After lesion, rats showed deficits in trained turning both contraand ipsilateral to the side of the lesion, with contralateral turning more severely impaired. The lesioned rats were then transplanted with fetal mesencephalic dopamine tissue into striatum. A control group of lesioned rats were sham transplanted. Four weeks after transplant, $1.5 \mathrm{mg} / \mathrm{kg} \mathrm{D}$-amphetamine challenge injections were used to test the functioning of the transplants. In the control rats, D-amphetamine induced ipsilateral turning; in transplanted rats, D-amphetamine slowed the rate of ipsilateral turning or reversed the direction of amphetamine-induced rotation. Only rats which reversed their amphetamine-induced turn direction after transplant were used for the rest of the experiment. Trained turning was assessed at $4,8,12$ and 16 weeks post transplant. Transplants did not improve learned performance at any time post transplant. When D-amphetamine was administered in conjunction with the trained turning sessions, a low dose $(0.12 \mathrm{mg} / \mathrm{kg})$ enhanced contralateral trained turn rates, without affecting ipsilateral turn rates. Higher doses of amphetamine reduced ipsilateral turn rate in the transplanted animals. The results of this study suggest that transplants alone do not reinstate performance of conditioned rotation.

\footnotetext{
${ }^{2}$ Author for correspondence.
}

\section{INTRODUCTION}

For over ten years, implants of fetal mesencephalic dopamine cells have been shown to survive and influence behavior in animals with unilateral lesions of the nigrostriatal bundle $/ 1,18 /$. When injected with amphetamine, animals with unilateral dopamine depletion will circle in the direction ipsilateral to the lesioned side. When injected with apomorphine, the same animals circle in the direction contralateral to the lesioned side. The amphetamine-induced ipsilateral circling is believed to be due to greater dopamine release in the striatum on the intact side compared to release in the striatum on the lesioned side. The apomorphine-induced contralateral circling is believed to be due to post-synaptic receptor supersensitivity on the lesioned side $/ 14,22 /$. Grafts of either solid pieces or cell suspensions of fetal mesencephalon implanted in the dopamine depleted striatum grow processes and change both amphetamine and apomorphine-induced rotation. Fetal nigral grafts slow down or even reverse the direction of amphetamine-induced rotation in unilaterally lesioned animals, while the rate of apomorphine-induced circling is reduced $/ 1,18 /$.

Several years ago, our laboratory developed the trained circling rat model in an effort to study changes in dopamine metabolism associated with conditioned motor behavior $/ 24 /$. Using this model, Dunnett and Björklund found that lesioned animals showed a reduction in their ability to acquire conditioned rotation in the direction contralateral to the lesioned side /6/. Subsequently, Dunnett et al. /10/ transplanted fetal mesencephalic tissue into lesioned animals and then studied the ability of the transplanted animals to acquire conditioned 
rotation. They found that grafted animals could learn to circle in the direction contralateral to the lesion better than lesioned controls but were worse than lesion alone in acquisition of conditioned rotation in the direction ipsilateral to the lesion. Recently, we reported the results of experiments in which animals were trained to circle in both the left and right directions for water reinforcement and then given unilateral dopamine lesions /20/. The results of that experiment indicated that unilateral dopamine lesions caused deficits in conditioned rotation both ipsilateral and contralateral to the lesioned side (although the contralateral deficit was more severe). In the present paper, we report the results of an experiment in which rats were trained to circle in both the left and right directions, then lesioned, and then implanted with fetal mesencephalic grafts.

\section{METHODS}

\section{Subjects}

Twenty-four male Sprague-Dawley rats weighing between 250 and $300 \mathrm{~g}$ at the start of training were used. They were housed 2-4 per cage under a 12:12 light dark cycle with access to food ad libitum. The rats were deprived of water for 23.5 hours during training and testing.

\section{Apparatus}

Turning was monitored automatically with four identical rotometers connected to VIC 20 microcomputers. These rotometers have previously been described in detail $/ 19 /$. Basically, the rotometers consisted of a shaft which was mounted in a bearing and attached to the rats by a length of model aircraft cable and a harness. A pointer fitted to the shaft interrupted beams from infrared-lightemitting diodes falling on an array of photo transistors as the animals turned. Output from the photo transistors was received by a computer which monitored the rats' turning movements and rewarded the rats for turns in the correct direction. The rats were confined by clear acrylic tubes (diameter $=20 \mathrm{~cm}$; height $=38 \mathrm{~cm}$ ) placed on a flat grid floor. A liquid dispenser (model 80201, Lafayetter Instrument Company) was used to provide $0.05 \mathrm{ml}$ water drops. The rotometers were placed inside the sound-attenuating chambers made of $5 \mathrm{~cm}$ thick Styrofoam. The sound-attenuating chambers were equipped with a fan and house light.

\section{Procedure}

The rats were trained to rotate in both left and right directions for water reinforcement. The animals were trained for 3 weeks ( 5 days a week) before receiving unilateral dopamine lesions. The pre-lesion baseline data used for analysis were taken from the last two days of this initial training period. Approximately 2 weeks after lesion surgery, the animals were tested for amphetamineinduced rotation. Then the rats were water deprived and retrained for one week in the trained turning task. The post-lesion turning data used for analysis were taken from the last two days of this second training period. Only rats which showed at least a $50 \%$ reduction in contralateral conditioned turning and which rotated greater than 150 net ipsilateral turns in response to amphetamine after lesion, were continued in the study. The 19 rats which met these criteria were divided into a transplant group and a control group. The 12 rats in the transplant group were implanted with fetal mesencephalic dopamine cells four weeks after lesion. The 7 rats in the control group were sham transplanted.

After transplantation, the rats were rested for two weeks with full access to water and then water deprived and trained for two weeks on the conditioned rotation procedure. This regimen was repeated four times. The rats were tested for 16 weeks on this testing regimen (i.e. rested for two weeks and then trained for two weeks). During this 16 week period the data from the last two days of each two week conditioned rotation test period were used for data analysis. In addition, the rats were tested for amphetamine-induced rotation once in every four week period. Of the 12 transplanted rats, six rats reversed their direction of amphetamine-induced turning by the end of the 16 week testing period (i.e. they circled contralateral rather then ipsilateral to the lesion); four rats slowed their rate of ipsilateral amphetamine rotation and 2 rats showed no effect of transplant on amphetamine-induced rotation. Only the six rats 
which reversed their direction of amphetamineinduced rotation were used for analysis of the ability of transplants to ameliorate deficits in trained turning caused by unilateral dopamine lesions.

At the end of the 16 week testing regimen described above, the rats in the transplant and control groups were given incremental doses of Damphetamine to evaluate the effects of amphetamine on trained turning. The doses of Damphetamine $(0.12,0.5$ and $1.5 \mathrm{mg} / \mathrm{kg})$ were given in ascending order, $15 \mathrm{~min}$ before the test session, twice a week with at least two days between each injection. Completion of the D-amphetamine dose effect curve required 4 weeks of testing ( 5 days a week).

Trained turning. The rats were trained to turn in both the left and right directions. The exact training procedure has been previously described /19/. Briefly, water deprived animals were placed in one of two chambers with different visual cues (light vs. dark). Half of the animals were reinforced with a drop of water $(0.05 \mathrm{ml})$ for turning left in the darkened chambers and right in the lighted chambers. The other half of the rats were reinforced for turning right in the dark chambers and left in the lighted chambers. The rats were placed in chambers associated with reinforcement of left and right turning on alternate days. For example, if on day 1 of training the rat was placed in the chamber where left turning was reinforced, then on day 2 of training the rat was placed in the chamber where right turning was reinforced. In this way, all rats were trained to turn in both directions on alternate days. The trained turning sessions consisted of 100 reinforced turns or 60 minutes, whichever occurred first.

Lesions. Unilateral dopamine depleting lesions were made by injecting 6-hydroxydopamine into the nigrostriatal tract /14/ (AP: $4.4 \mathrm{~mm}$ posterior to bregma; L: $0.9 \mathrm{~mm}$ to the right of midline; V: 7.5 $\mathrm{mm}$ below dura; nose bar set at $2.3 \mathrm{~mm}$ below the interaural line). The rats were infused with $8 \mu \mathrm{g}$ (free base) of 6-hydroxydopamine in $4 \mu \mathrm{l}$ of 0.2 $\mathrm{mg} / \mathrm{ml}$ ascorbic acid/saline solution. The infusions were made through a 30-gauge stainless steel cannula over a six-minute period and then left in place for two minutes after injection. The rats were pre-treated with the noradrenergic uptake blocker desipramine $(15 \mathrm{mg} / \mathrm{kg}$ i.p.) and atropine sulfate sulfate $(0.01 \mathrm{mg} / \mathrm{kg}$ i.p.) and then anesthetized with $150 \mathrm{mg} / \mathrm{kg}$ chloral hydrate and $50 \mathrm{mg} / \mathrm{kg}$ ketamine. The rats were allowed full access to water for 2 weeks after surgery.

Amphetamine-induced rotation. The rats were injected with $1.5 \mathrm{mg} / \mathrm{kg} \mathrm{D}$-amphetamine i.p. and then immediately placed in the rotometers for a two hour test session. The number and direction of amphetamine-induced rotations were measured using the same apparatus described above except that there were no water feeders mounted on the walls of the test cylinders. All of the chambers were illuminated. Half the rats were tested for amphetamine-induced rotation in chambers in which they had previously been trained to turn right and half of the rats were tested in chambers in which they had previously been trained to turn left. The rats had free access to water in their home cages for at least $48 \mathrm{~h}$ prior to testing for amphetamine-induced rotation.

Transplants. The animals were transplanted with rat fetal mesencephalic dopamine cells dissected from embryos with crown rump lengths of $12-15 \mathrm{~mm}$. After dissection the tissue was placed in cold lactated Ringer's solution $(10 \mu \mathrm{l}$ per fetus) and minced by cutting with fine scissors. The tissue was then aspirated first into a 19 gauge needle and then pulled/pushed into the 21 gauge transplant cannula. This procedure resulted in a coarse cell suspension. The rats received injections of cell suspensions along five different tracks within the striatum [track 1: (AP) $3.4 \mathrm{~mm},(\mathrm{ML})$ $2.0 \mathrm{~mm}$, (DV) $4.5-7.5 \mathrm{~mm}$; track 2: (AP) $2.4 \mathrm{~mm}$, (ML) $2.0 \mathrm{~mm}$, (DV) $4.0-7.0 \mathrm{~mm}$; track 3: (AP) 2.4 $\mathrm{mm}$, (ML) $3.5 \mathrm{~mm}$, (DV) $4.0-7.0 \mathrm{~mm}$; track 4: (AP) $1.4 \mathrm{~mm}$, (ML) $3.5 \mathrm{~mm}$, (DV) $4.0-7.0 \mathrm{~mm}$; track 5: (AP) $0.2 \mathrm{~mm}$, (ML) $4.0 \mathrm{~mm}$, (DV) 4.0 - 7.0 $\mathrm{mm}]$. The AP coordinates were anterior to bregma, the ML coordinates were to the right of midline and the DV coordinates indicate distance below dura. The nose bar was set at $+5.0 \mathrm{~mm} / 17 /$. Approximately $3 \mu \mathrm{l}$ of the cell suspension were injected along each track. Control rats were sham transplanted with injections of the lactated Ringer's solution. 
Histology and biochemistry. Transplanted animals were sacrificed with an overdose of pentobarbital followed by intracardiac perfusion with cold heparinized saline and $4 \%$ paraformaldehyde. After fixation, the brains were blocked and left for 24 hours in a $30 \%$ sucrose solution. The portion of the striatum containing the transplant tracts was then sectioned (40 microns) using a freezing microtome. Tyrosine hydroxylase immunohistochemistry was performed on the brain sections using rabbit derived antibody to tyrosine hydroxylase supplied by Pel Freeze (Rogers, AR) and goat antirabbit peroxidase linked antibody supplied by Vector Laboratories (Burlingame, CA). Diaminobenzidine was used as the substrate for the peroxidase reaction.

The resulting brain sections for each rat were evaluated in order to determine the extent of graft survival. Representative brain sections at each transplantation site were selected for evaluation. The transplants at each site were rated according to a scale which included high, moderate and low ratings. High indicated that a large number of tyrosine hydroxylase positive cells were associated with the track and there was dense innervation of the surrounding host tissue. Moderate indicated that tyrosine hydroxylase positive cell bodies were associated with the track and there was a moderate level of innervation in the surrounding tissue. A moderate rating was sometimes given to transplants which had a large number of tyrosine hydroxylase positive cells in the transplant, but which did not innervate the surrounding host tissue. Low indicated the presence of at least one tyrosine hydroxylase positive cell body in the transplant with few fibers present in the surrounding host tissue. If no tyrosine hydroxylase positive cell bodies were found associated with the transplant track, then no rating was made.

Control animals were sacrificed and striatal tissue from both sides of brain was assayed for dopamine content using high pressure liquid chromatography as previously described $/ 20 /$.

Data analysis. The amphetamine-induced rotation data were analyzed using a mixed two-way analysis of variance with transplant as the between subject variable and weeks as the within subject variable. The dependent variable was net number of turns in the ipsilateral direction (ipsilateral turns - contralateral turns). The conditioned rotation data were also analyzed with transplant as the between subject variable and weeks as the within subject variable. Ipsilateral turn rate and contralateral turn rate were analyzed separately. The amphetamine dose response curve with turn rate data was analyzed using a mixed two-way analysis of variance with transplant as the between subject variable and dose as the within subject variable. Ipsilateral turn rate and contralateral turn rate were analyzed separately. In all cases, post hoc analysis was performed using a Tukey test for unconfounded means $/ 23 /$. Results of analysis of variance and post hoc tests are summarized in the figure captions.

\section{RESULTS}

\section{Amphetamine-induced rotation}

Transplantation with fetal mesencephalic dopamine cells reversed the direction of amphetamine-induced rotation. Figure 1 shows amphetamine-induced rotation over the course of the experiment for the 7 control and 6 transplanted rats. After 6-hydroxydopamine lesion but before transplantation, the transplant and control groups were not different in the net number of rotations ipsilateral to the lesioned side induced by amphetamine. After transplantation there was a large difference between the transplant and control groups in amphetamine-induced turning. The six rats in the transplant group were chosen because they reversed their direction of amphetamineinduced rotation after transplantation (i.e. their net rotation scores were negative indicating that they rotated more often contralateral to the lesioned side). The difference between the transplant and control groups in amphetamine-induced rotation persisted for the duration of the experiment.

\section{Conditioned rotation}

Transplantation with fetal mesencephalic dopamine cells failed to ameliorate the deficits observed with trained turning after unilateral dopamine lesions. The bottom graph in Figure 2 


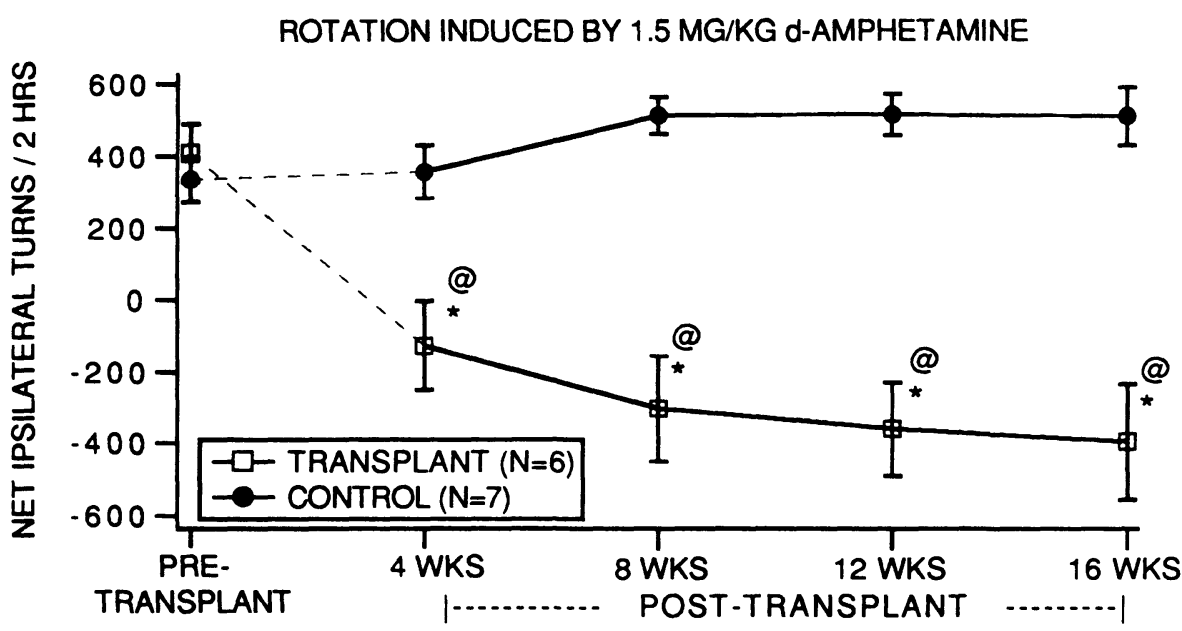

Fig. 1: The direction of amphetamine-induced turning in animals with unilateral dopamine lesions was reversed by transplantation with fetal mesencephalic dopamine cells. Transplant animals were lesioned with 6-hydroxydopamine and transplanted with fetal mesencephalic dopamine cells. Control animals were lesioned with 6-hydroxydopamine and sham transplanted. The overall $F$ test indicated significant main effects and interaction terms: transplant, $F(1,11)=32.165$, $\mathrm{p}<0.001$; week, $F(4,44)=6.401, \mathrm{p}<0.001$; and interaction, $F(4,44)=16.215, \mathrm{p}<0.0001 .{ }^{*}$ indicates significantly different from pre-transplant baseline; @ indicates that the transplant group was significantly different from the corresponding control group, $\mathrm{p}<0.05$.

shows that unilateral dopamine lesions caused deficits in conditioned rotation contralateral to the lesioned side. The top graph in Figure 2 shows that unilateral dopamine lesions also caused deficits in conditioned rotation ipsilateral to the lesioned side (although the contralateral deficit was larger). Both the ipsilateral and contralateral deficits persisted over the 20 week post-lesion observation period. After transplantation, both control and transplant groups showed a small increase in the rate of contralateral conditioned rotation. However, there was no differential effect of transplant on trained rotation.

\section{Effects of amphetamine on conditioned rotation}

Amphetamine affected conditioned rotation in the transplant and control rats differentially. The top graph in Figure 3 shows the effects of amphetamine on ipsilateral conditioned rotation 16 to 20 weeks after transplant. In the transplanted animals the rate of ipsilateral rotation was significantly decreased at the 0.5 and $1.5 \mathrm{mg} / \mathrm{kg}$ doses of amphetamine. Amphetamine had no significant effect on ipsilateral conditioned rotation in the control animals. The bottom graph in Figure 3 shows the effects of amphetamine on contralateral rotation. In the transplanted animals the rate of contralateral rotation was increased at the 0.12 and $0.5 \mathrm{mg} / \mathrm{kg}$ doses of amphetamine. At the highest dose, $1.5 \mathrm{mg} / \mathrm{kg}$, amphetamine no longer enhanced contralateral trained circling. Behavior was disrupted at this dose. Amphetamine had no significant effect on contralateral conditioned rotation in the control animals.

The results shown in Figure 3 indicate that in the transplant group, amphetamine increased the rate of contralateral conditioned rotation and decreased the rate of ipsilateral conditioned rotation. Amphetamine at the doses tested had no significant effect on the rate of conditioned rotation in the control group.

\section{Histology and biochemistry}

Visualization of the transplants with tyrosine hydroxylase immunohistochemistry indicated that all six rats in the transplant group had grafts with surviving dopamine neurons. The density and location of tyrosine hydroxylase positive cells for each of the six transplanted rats is indicated in Figure 4. The transplants did not produce a major distortion of the striatum.

The seven rats in the control group were found 

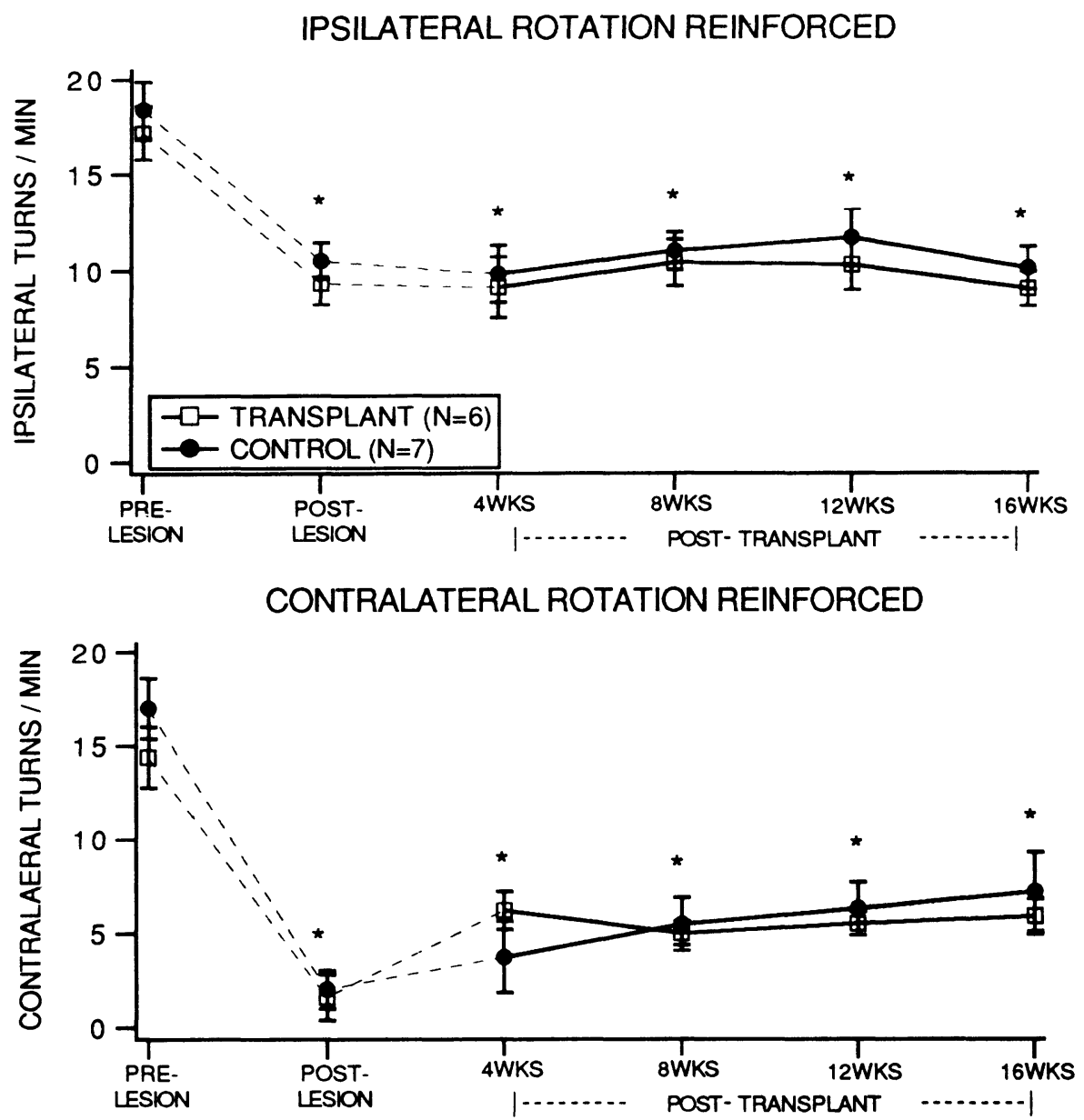

Fig. 2: Unilateral dopamine lesions caused deficits in trained turning in both the ipsilateral and contralateral directions (although the contralateral deficit was more severe). Transplantation with fetal mesencephalic dopamine cells did not ameliorate these lesion-induced deficits. The overall $F$ test for the ipsilateral direction indicated a significant main effect of weeks; the main effect of transplant and the interaction term were not significant: ipsilateral week, $F(5,55)=21.476, p<0.0001$. The overall $\mathrm{F}$ test for the contralateral direction indicated a significant main effect of weeks; the main effect of transplant and the interaction term were not significant: contralateral week, $F(5,55)=57.782, p<0.0001 .{ }^{*}$ indicates significant difference from pre-lesion baseline, $\mathrm{p}<0.05$.

to have large depletions of dopamine in the striatum ipsilateral to the lesion. The concentration of dopamine in the striatum ipsilateral to the lesion was $3.63 \pm 1.48 \mathrm{nmol} / \mathrm{g}$ tissue (mean $\pm \mathrm{SEM}$ ). The concentration of dopamine in the striatum contralateral to the lesioned side was $87.3 \pm 9.6$ $\mathrm{nmol} / \mathrm{g}$ (mean $\pm \mathrm{SEM}$ ). Dopamine levels on the lesioned side were $4.02 \pm 1.56$ (mean \pm SEM) percent of the contralateral side.

\section{DISCUSSION}

Changes in amphetamine or apomorphineinduced circling in rats with unilateral 6hydroxydopamine lesions have been generally used to demonstrate the behavioral effectiveness of fetal mesencephalic dopamine cell grafts $/ 1,8,18 /$. Few studies have attempted to show the effectiveness of fetal mesencephalic dopamine cell grafts for 
IPSILATERAL ROTATION REINFORCED

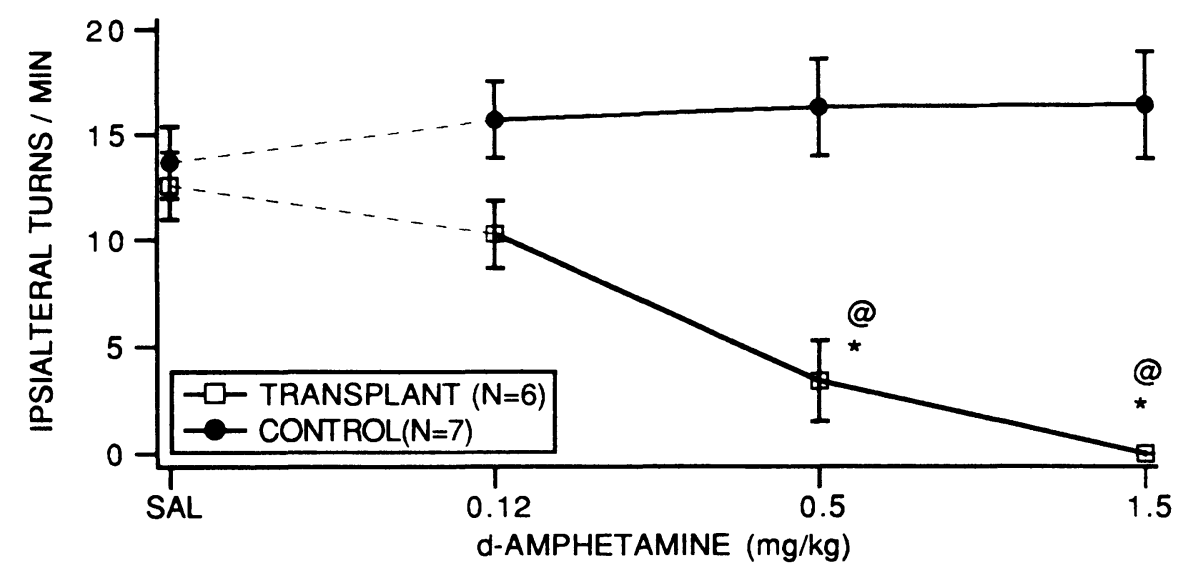

\section{CONTRALATERAL ROTATION REINFORCED}

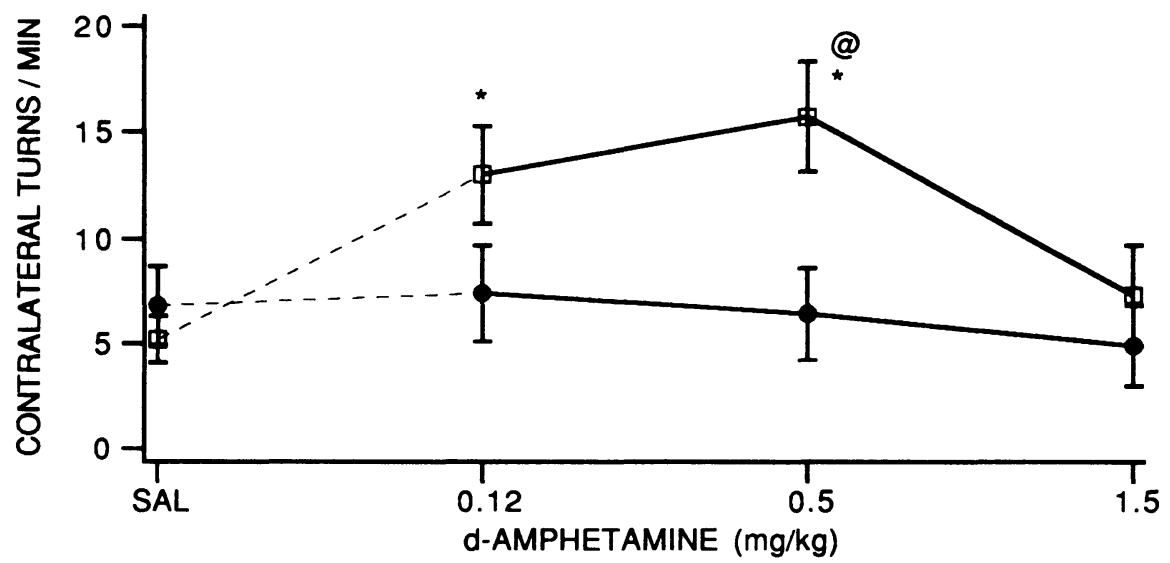

Fig. 3: Amphetamine differentially affected trained turning in the transplant and control groups 16 to 20 weeks after transplant. In the transplant group, amphetamine increased the rate of turning in the contralateral direction while it decreased the rate of turning in the ipsilateral direction. In the control group, amphetamine did not significantly change turn rate in either the contralateral or ipsilateral directions. The overall $\mathrm{F}$ test for the ipsilateral direction indicated a significant main effect of transplant and dose; the interaction term was also significant: ipsilateral transplant, $F(1,11)=16.311, p<0.01$; ipsilateral dose, $F(3,33)=8.455, p<0.001$; ipsilateral interation, $F(3,33)=17.599, p<0.0001$. The overall $F$ test for the contralateral direction indicated a significant main effect of dose and interaction term, the main effect of transplant was not significant: contralateral dose, $F(3,33)=7.978$, $p<0.001$; contralateral interaction, $F(3,33)=6.073$, $p<0.01$. *indicates significant difference from pre-transplant baseline; @ indicates that the transplant group was significantly different from the corresponding control group, $p<0.05$.

restoring learned, goal directed behaviors. In the present experiment we have evaluated the effects of unilateral lesions and transplants in animals which had been trained to rotate in both the left and right directions. We found that transplants which reversed the direction of amphetamine-induced rotation did not ameliorate deficits in trained rotation. There was no indication that transplants affected conditioned rotation in either the contralateral or ipsilateral directions. The results of this study are different from the observations by Dunnett and colleagues who found that lesioned, transplanted animals could acquire contralateral conditioned rotation better than animals with 


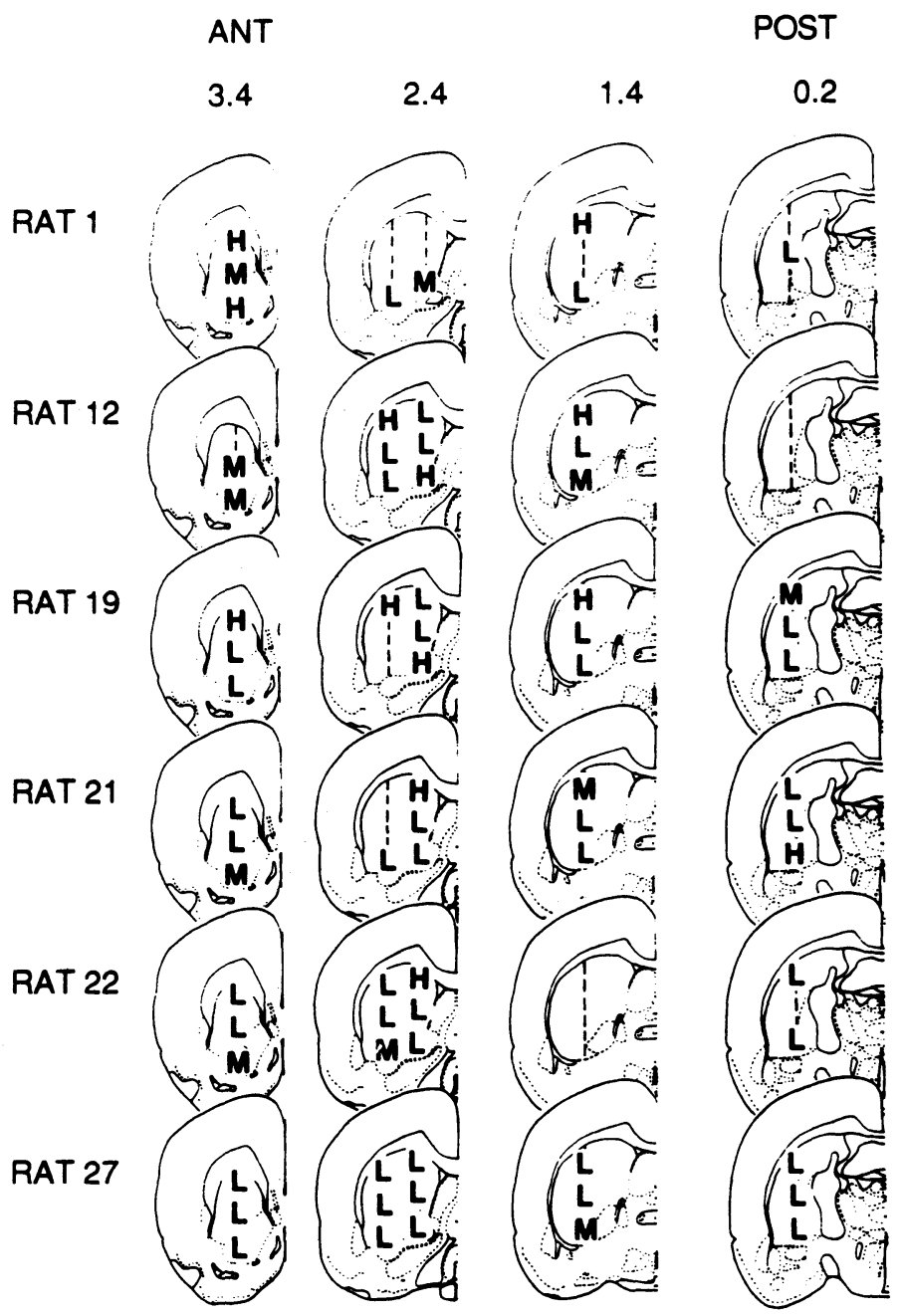

Fig. 4: Evaluation of transplant sites with tyrosine hydroxylase immunohistochemistry indicated surviving transplants in all 6 rats in the transplant group. The transplants were evaluated using a rating scale which included high, moderate and low rating $(\mathrm{H}=$ high; $\mathrm{M}=$ moderate; $\mathrm{L}=\mathrm{low})$. The dashed lines indicate transplant tracks with no tyrosine hydroxylase positive cells.

lesions alone /10/. Dunnett et al. also observed that transplants interfered with ipsilateral conditioned rotation. We found that transplants had no influence on trained circling in the ipsilateral direction.

There are many differences in procedure involving training, apparatus and transplants between the present study and the Dunnett et al. /10/ study which could account for the inconsistent results. For example, Dunnett et al. studied acquisition, while the present study evaluated performance of a previously acquired task. In addition, the deficits observed after unilateral dopamine lesions were not the same. Dunnett and colleagues found no deficits in ipsilateral conditioned turning compared to controls after unilateral lesions whereas our study did, replicating a previously reported result from our laboratory $120 \%$

Other groups have found that fetal dopamine cell implants fail to ameliorate deficits in non-drug. induced behaviors caused by dopamine lesions. Generally, these negative studies have involved motivated behaviors: feeding, drinking and 
reaching for food $/ 3,7,11,12,16 /$. Studies which report positive effects of grafts on non-druginduced behaviors have generally involved postural control and orientation $/ 9,11 /$.

While transplants were unsuccessful at restoring trained circling behavior by themselves, a low dose of amphetamine $(0.12 \mathrm{mg} / \mathrm{kg})$ led to a doubling of conditioned rotation rate in the direction contralateral to the transplant. This dose did not affect conditioned rotation in the ipsilateral direction, suggesting that the increased rate of turning in the contralateral direction was not simply induced by the drug. Further augmentation of contralateral trained turning was seen after a dose of $0.5 \mathrm{mg} / \mathrm{kg}$ amphetamine. However, the 0.5 $\mathrm{mg} / \mathrm{kg}$ dose of amphetamine decreased ipsilateral rotation, suggesting that contralateral rotation was induced in part by the drug. The highest dose of amphetamine, $1.5 \mathrm{mg} / \mathrm{kg}$, reduced conditioned rotation to a level no better than control. When given the $0.12 \mathrm{mg} / \mathrm{kg}$ and $0.5 \mathrm{mg} / \mathrm{kg}$ doses the rats consumed the water reinforcer after each turn. In contrast, at the $1.5 \mathrm{mg} / \mathrm{kg}$ dose, some of the transplanted animals appeared to be turning in response to amphetamine alone since they did not consume the water reinforcer as they rotated. For ipsilateral trained circling, amphetamine caused a progressive reduction in the ability of the transplanted animals to circle for reward. For circling in the ipsilateral direction, release of dopamine from the transplant appears to interfere with performance of conditioned rotation.

One interpretation of these results is that amphetamine may have a dual action on transplant mediated behaviors. At low doses, the drug may release enough dopamine from the implants to facilitate conditioned behaviors without having disruptive effects. At higher doses, the induction of dopamine release from the implant appears to disrupt the circuitry required to express conditioned behaviors. This interpretation of the results is speculative, however. The conditioned behavior of contralateral turning was confounded, since the behavior induced by amphetamine was also contralateral turning. For this reason it is very difficult to differentiate between the effects of amphetamine on drug-induced behaviors and the effects of amphetamine on conditioned behaviors using the trained turning paradigm. The observed effects of the $0.12 \mathrm{mg} / \mathrm{kg}$ dose of amphetamine in the transplanted animals could represent an interaction of a drug-induced increase in the tendency to turn in the contralateral direction and conditioned contralateral turning. More convincing evidence that low doses of amphetamine facilitate the ameliorative effects of fetal dopamine cell implants would require a behavioral paradigm where the target behavior being restored by the graft is different from the behavior(s) induced by amphetamine.

In this experiment we found that implantation with fetal mesencephalic tissue led to good graft survival and physiologic function as measured by amphetamine-induced circling. On the other hand, the grafts were not useful for restoring trained circling behavior either contralateral or ipsilateral to the side of the transplant. Because dopamine cell grafts lack normal afferent input, it is possible that deficits in performance of learned behaviors are the result of this lack of innervation. A number of studies have shown that the performance of learned and motivated behaviors is accompanied by increased dopamine cell firing $/ 5,15 /$ and release of dopamine $/ 2,4,13,21,25 /$. Dopamine implants may not be capable of releasing the dopamine required to support the performance of learned and motivated behaviors in response to environmental demands.

\section{ACKNOWLEDGEMENTS}

This work was supported by USPHS grants NS 18639 and GM 07063.

\section{REFERENCES}

1. Björklund A, Stenevi U. Reconstruction of the nigrostriatal dopamine pathway by intracerebral nigral transplants. Brain Res 1979; 177: 555-560.

2. Blackburn JR, Phillips AG, Jakubovic A, Fibiger HC Dopamine and preparatory behavior: II. A neurochemical analysis. Behav Neurosci 1989; 103: 15-23.

3. Choulli K, Herman JP, Rivet JM, Simon H, LeMoal M. Spontaneous and graft-induced behavioral recovery after 6-hydroxydopamine lesion of the nucleus accumbens in the rat. Brain Res 1987; 407: 376-380.

4. Church WH, Justice JB, Neill DB. Detecting behaviorally relevant changes in extracellular 
dopamine with microdialysis. Brain Res 1987; 412: 397-399.

5. Diana M, Garcia-Munoz M, Richards JB, Freed CR. Electro-physiological analysis of dopamine cells from the substantia nigra pars compacta of circling rats. Exp Brain Res 1989; 74: 625-630.

6. Dunnett SB, Björklund A. Conditioned turning in rats: Dopaminergic involvement in the initiation of movement rather than the movement itself. Neurosci Lett 1983; 41: 173-178.

7. Dunnett SB, Björklund A, Schmidt RH, Stenevi U. Intracerebral grafting of neuronal cell suspensions: V. Behavioral recovery in rats with bilateral 6-OHDA lesions following implantation of nigral cell suspensions. Acta Physiol Scand 1983; 522: 39-47.

8. Dunnett SB, Björklund A, Schmidt RH, Stenevi U, Iversen SD. Intracerebral grafting of neuronal cell suspensions. IV. Behavioral recovery in rats with unilateral 6-OHDA lesions following implantation of nigral cell suspensions in different forebrain sites. Acta Physiol Scand 1984; 522: 29-37.

9. Dunnett SB, Björklund A, Stenevi U. Iversen SD. Grafts of embryonic substantia nigra innervating the ventrolateral striatum ameliorate sensorimotor imapirments and akinesia in rats with 6-OHDA lesions of the nigrostriatal pathway. Brain Res 1981; 229: 209. 217.

10. Dunnett SB, Whishaw IQ, Jones GH, Isacson O. Effects of dopamine rich grafts on conditioned rotation in rats with unilateral 6-hydroxydopamine lesions. Neurosci Lett 1986; 68: 127-133.

11. Dunnett SB, Whishaw IQ, Rogers DC, Jones GH. Dopamine-rich grafts ameliorate whole body motor asymmetry and sensory neglect but not independent skilled limb use in rats with 6-hydroxydopamine lesions. Brain Res 1987; 415: 63-78.

12. Herman JP, Choulli K, Geffard M, Nadaud D, Taghzouti K, LeMoal M. Reinnervation of the nucleus accumbens and frontal cortex of the rat by dopaminergic grafts and effects on hoarding behavior. Brain Res 1986; 372: 210-216.

13. Hernandez L, Hoebel BG. Feeding and hypothalamic stimulation increase dopamine turnover in the accumbens. Physiol Behav 1988; 44: 599-606.

14. Marshall JF, Ungerstedt U. Supersensitivity to apomorphine following destruction of the ascending dopamine neurons: Quantification using the rotational model. Eur J Pharmacol 1977; 41: 361-367.

15. Miller JD, Sanghera MK, German DC. Mesencephalic dopaminergic unit activity in the behaviorally conditioned rat. Life Sci 1981; 29: 1255-1263.

16. Montoya CP, Astell S, Dunnett SB. Effects of nigral and striatal grafts on skilled forelimb use in the rat. Prog Brain Res 1990; 82: 459-466.

17. Pellegrino LJ, Pellegrino AS, Cushman AJ. A Stereotaxic Atlas of the Rat Brain. New York: Plenum Press, 1979.

18. Perlow MJ, Freed WJ, Hoffer BJ, Seiger A, Olson L, Wyatt RJ. Brain grafts reduce motor abnormalities produced by destruction of nigrostriatal dopamine system. Science 1979; 204: 643-647.

19. Richards JB, Sabol KE, Freed CR. Conditioned rotation: A behavioral analysis. Physiol Behav 1990; 47: 1083-1087.

20. Richards JB, Sabol KE, Freed CR. Unilateral dopamine depletion causes bilateral deficits in conditioned rotation in rats. Pharmacol Biochem Behav 1990; 36: 217-223.

21. Sabol KE, Richards JB, Freed CR. In vivo dialysis measurements of doapmine and DOPAC in rats trained to turn on a circular treadmill. Pharmacol Biochem Behav 1990; 36: 21-28.

22. Ungerstedt U. Striatal dopamine release after amphetamine or nerve degeneration revealed by rotational behavior. Acta Physiol Scand 1971; 82, suppl 367: 49-68.

23. Winer BJ. Statistical Principles in Experimental Design. New York: McGraw-Hill, 1971; 907 pp.

24. Yamamoto BK, Freed CR. The trained circling rat: A model for inducing unilateral caudate dopamine metabolism in normal brain. Nature 1982; 298: 467 468.

25. Yamamoto BK, Lane RF, Freed CR. Normal rats trained to circle show asymmetric caudate dopamine release. Life Sci 1982; 30: 2155-2162. 

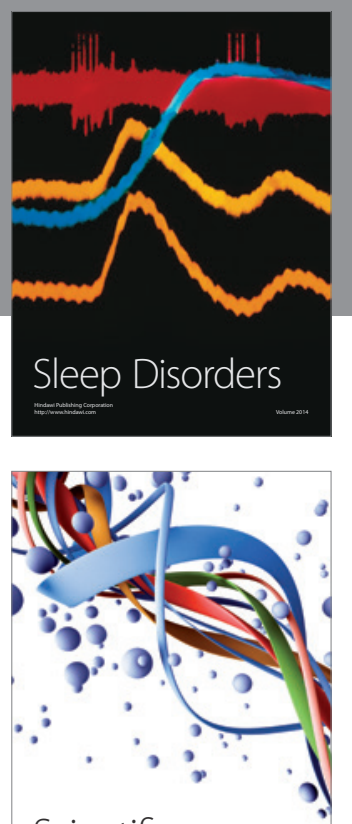

Scientifica
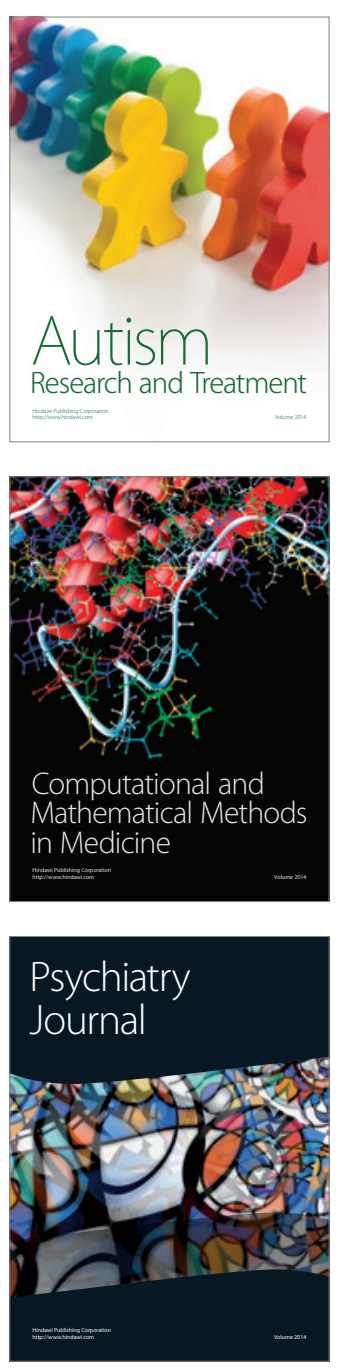
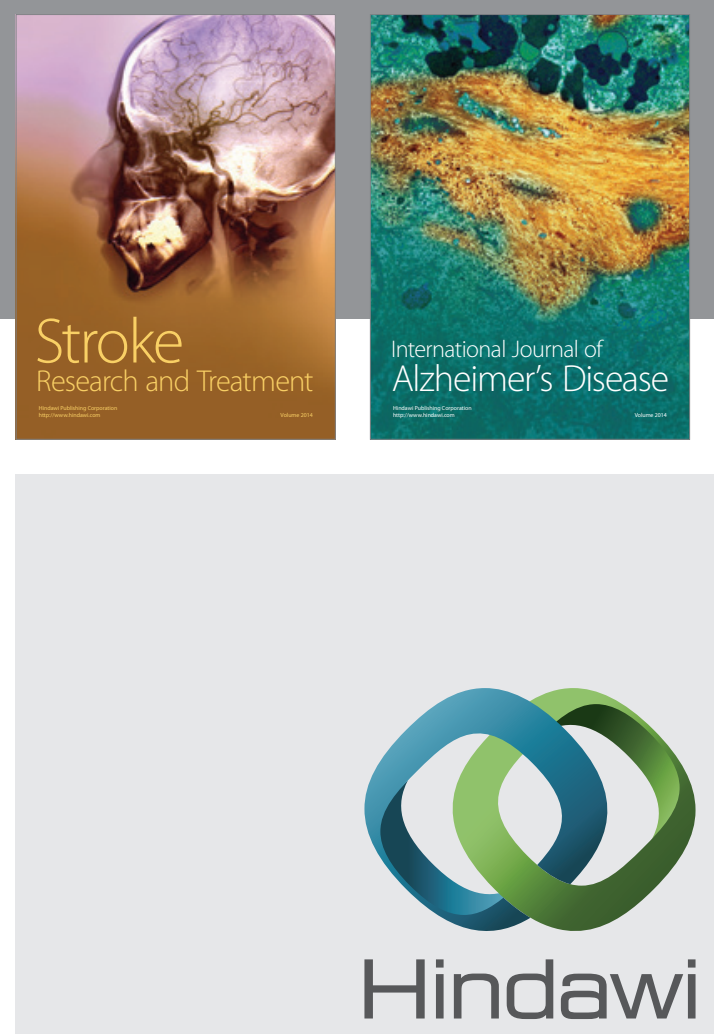

Submit your manuscripts at

http://www.hindawi.com
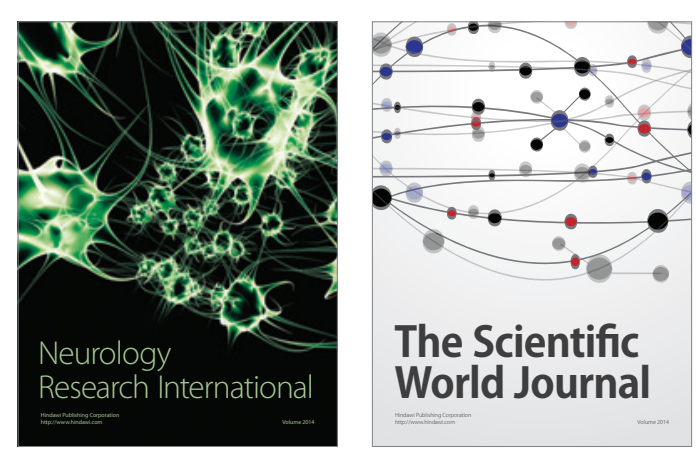

The Scientific World Journal

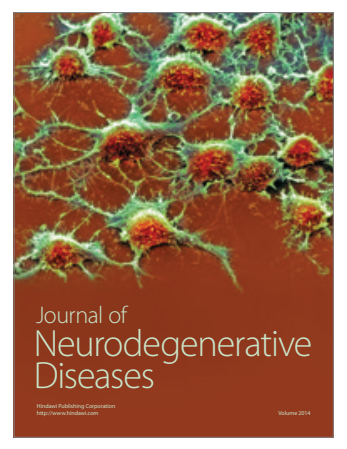

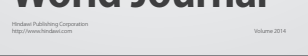

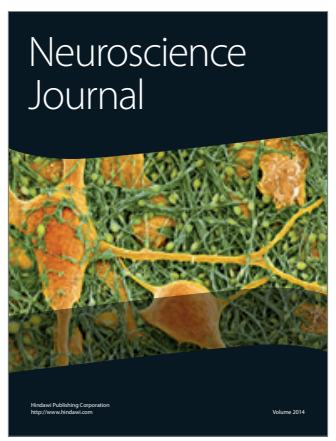

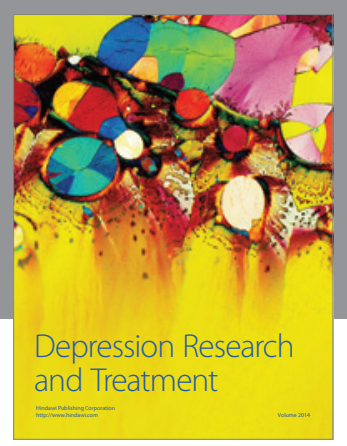
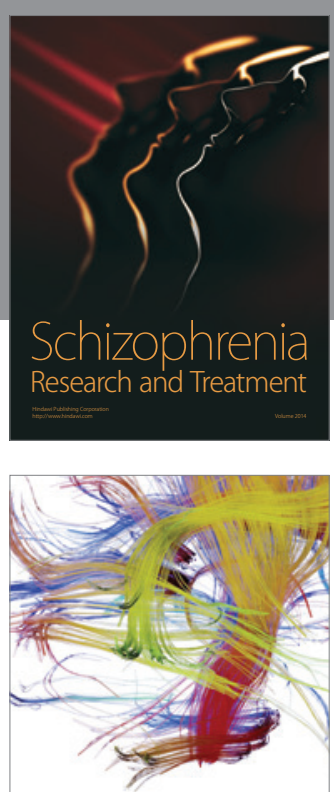

Brain Science

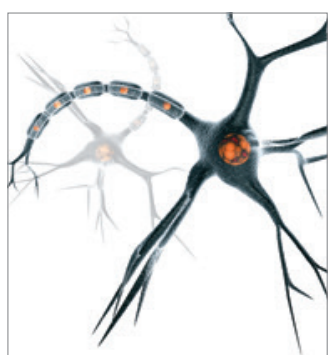

Neural Plasticity
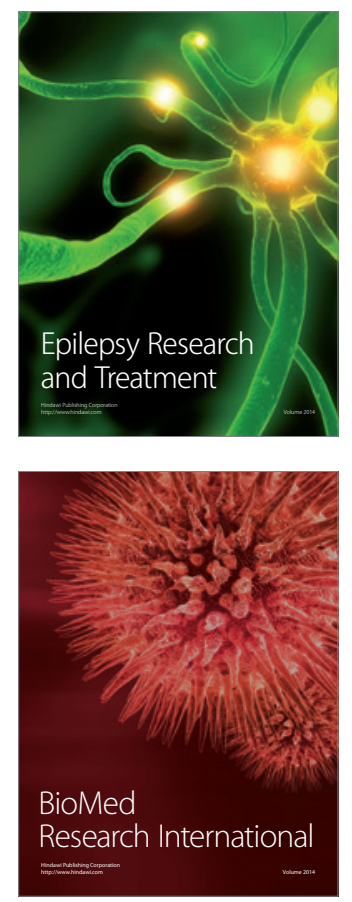

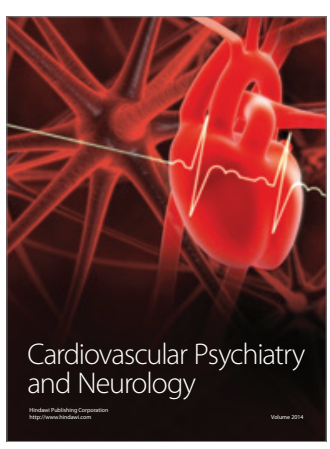

Parkinson's

Disease
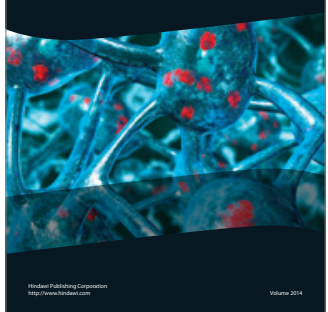